\title{
Fusion project 'should wait for US results'
}

Washington. The International Thermonuclear Experimental Reactor (ITER) should be delayed for between three and five years to allow the United States first to fund its own fusion experiment, the Tokamak Physics Experiment (TPX) at Princeton, New Jersey, according to a leading congressional supporter of the fusion programme.

The comments come shortly before the release of a report from the congressional Office of Technology Assessment (OTA), which is expected to castigate the US Department of Energy (DoE) for the lack of coordination between the two main magnetic fusion programmes, ITER and TPX, and to suggest that TPX would be a far more useful experiment if ITER were delayed to incorporate its results.

ITER, which is being planned jointly with research teams in Europe, Japan and Russia, is now in the design stage, with construction scheduled in principle to begin in 1998. But George Brown (Democrat, California), the ranking minority member of the House of Representatives Science Committee, and one of ITER's strongest backers in Congress, said last week that the possibility of a delay should be examined before going ahead with construction. "We should examine that with our international partners. I can foresee a pause of three to five years."

OTA's unpublished report, The Fusion Energy Program: The Role of TPX and Alternative Concepts, says that the value of TPX to the magnetic fusion programme "could increase" if ITER were delayed. At present, it says, the planned schedule of the two projects prevents TPX results from feeding into the design and construction of ITER. This could only happen, it says, if ITER construction were delayed for "several years".

Robert Aymar, director of ITER, immediately rejected the idea of a delay to wait for TPX. "It's completely out of the question," he said. According to Aymar, TPX would not yield results until 2005, and a delay until then "was like saying not to continue ITER at all".

TPX is designed to test a number of innovations in fusion reactor design, including the use of superconducting magnets and, most importantly, the use of a controlled current profile to sustain fusion in a socalled "second stability regime" of higher density than has been managed before.

Stephen Dean, president of Fusion Power Associates and an acknowledged fusion expert, claims that the construction of an ITER prototype would be smaller, and 20 40 per cent cheaper, if built on the basis of a successful TPX experiment.

The OTA report also disputes the DoE's contention that it needs $\$ 100$ million to carry out research into alternatives to tokamaks, the doughnut-shaped fusion chambers on which TPX and ITER would be based. It says that useful paper studies of alternatives could be conducted for only a few million dollars.

The postponement of the ITER would relieve pressure on the department's magnetic fusion research budget $-\$ 373$ million this year - which is too small to support ITER, TPX and the supporting basic research programmes (see Nature 372, 493; 1993).

But the proposal will raise difficult new questions, such as whether the money now being spent on ITER design, planned at $\$ 150$ million this year in the United States alone, is being wasted if the project is delayed and then redesigned.

President Bill Clinton's budget proposal for the fiscal year beginning on 1 October,

\section{Threat to German medical research}

Munich. Medical research is suffering because of the priority being given to short-term patient care, according to Germany's science council, the Wissenschaftsrat. In a report published last week, it says that major changes must be made in the management of teaching hospitals to increase the decision-making powers of academic faculty and ensure that funds intended for research are not diverted to patient care.

Most teaching hospitals operate with a single budget for patient care, teaching and research, and distribution of funds between these functions is often obscure. The Wissenschaftsrat wants accounting to be more transparent, and teaching hospitals to maintain separate budgets for teaching and research.

In many cases, decisions about the distribution of funds are made by the clinical faculty without consulting academic staff, says Gisela Frank, head of the Wissenschaftsrat's medical research team. "When money becomes tight, this creates a conflict between patient care and research and teaching," she says.

The problem is particularly pressing because of fears that a new health-care law will lead teaching hospitals to cut funds for research. Under the new law, which has already frozen funding at 1993 levels and comes into full force in 1996, health insurance will no longer pay the hospitals' actual costs, but only the estimated average cost of each patient procedure. This, it is hoped, will encourage hospitals to keep costs down.

But many fear that the move will penalize teaching hospitals, which receive between 60 and 90 per cent of their funding from national insurance, and the rest from local governments. As they treat unusual and severe cases, and require more staff to train new doctors, teaching hospitals are often more expensive than due to be revealed next week, is likely to continue funding for fusion at roughly the present level. But administration officials have said that their plans will be revised in the light of two reports due in the spring one on research priorities from a DoE advisory panel, the other on fusion from the President's Committee of Advisors on Science and Technology (PCAST).

The attitude towards fusion of the new Congress, where budgets will be finally set, remains untested. But one certainty, as Dean points out, is that dollars will be even harder to find for an international project such as ITER than for the all-American TPX.

Colin Macilwain

community hospitals. If they are to receive less money from health insurance, researchers fear that clinicians will fight for a higher share of the local government money that supports research.

But separating expenditures is not easy, says Klaus Peter, dean of the medical school at the Ludwig Maximilian University in Munich. "Clinical costs represent 30 to $\mathbf{4 0}$ per cent of the operating budget, and research and teaching 20 per cent, but it is impossible to separate and specify the rest."

For example, while facilities such as outpatient clinics are part of patient care, they are also essential for training doctors. Peter Gaehtgens, a physiologist and, until recently, vice-president of the medical faculty of the Free University of Berlin, says that national health insurance does not recognize this overlap, nor does it cover such services adequately. The result is that less money remains for research.

The Wissenschaftsrat also recommends closing or combining some facilities. In particular, it suggests that the two medical schools in Munich should combine some of their facilities, and that 600 beds from Munich and other hospitals in Bavaria should be closed to free funds for research. "This will not harm patient care, since more procedures are being handled on an outpatient basis", says Gaehtgens.

The recommendations of the Wissenschaftsrat, whose members include both scientists and politicians, are influential at the federal level. Although teaching hospitals are almost entirely locally funded, half of the costs of new buildings and major items of equipment are paid by the federal government which is why the hospitals are already starting to implement the advisory group's proposals.

Toni Feder 